EPiC Series in Engineering
Volume 3, 2018, Pages 2011-2018
HIC 2018. 13th International
Conference on Hydroinformatics

\title{
Decision making methods for water resources planning in England and Wales
}

\author{
Damian Staszek ${ }^{1}$, Dragan Savic ${ }^{1}$, Guangtao $\mathrm{Fu}^{1}$ \\ ${ }^{1}$ College of Engineering, Mathematics and Physical Sciences, University of Exeter, \\ Streatham Campus, North Park Road, Exeter, Devon EX4 4QF, United Kingdom \\ ds463@exeter.ac.uk
}

\begin{abstract}
Water companies in England and Wales use a range of decision making methods (DMMs) for water resources planning. The aim of this paper is to provide a critical review of the DMMs employed by water companies in relation to their 2014 Water Resources Management Plan (WRMP) submissions; as compared with those used for the current round of draft 2019 WRMP submissions. Most companies use a similar suite of models to assess their supply-demand situation. For previous submissions, target headroom approach was the preferred method for representing the uncertainty in water resources planning. For the recent round of draft WRMP submissions, some companies have decided to investigate more advanced DMMs, and to choose risk-based methods in order to select their preferred investment scenarios. Bristol Water, Severn Trent Water, Southern Water and Thames Water have still chosen the Economics of Balancing Supply Demand (EBSD) method for selecting their optimal investment programmes; but Thames Water have decided to progress to simulation methods (Multi Criteria Search) for optimal investment selection where zones with more complex supply demand problems are concerned. Only Thames Water decided to use a multiple linear regression model for household consumption forecast, the remaining companies used micro-component analysis for this purpose.
\end{abstract}

Keywords: Decision making methods, headroom, regulation, Water Resources Management Plan

\section{Introduction}

Water companies in England and Wales are required to submit Water Resources Management Plans (WRMPs) to their regulators every 5 years. WRMPs contribute to Business Plan submissions, as investments selected during WRMP are funded through Ofwat's (economic regulator) price review process [1]. 
Water companies operate under pressure to provide services that will meet customers' expectations in the most cost-effective way. Future demands and supplies as well as their variability due to population growth and climate change impact need to be incorporated into water resource planning $[2,3]$. Companies are required to produce separate supply and demand forecasts, and then use supply-demand balance modelling tools to decide on future options. A range of decision-support tools is employed by companies in order to evaluate their potential investment planning scenarios with a view to ensuring that the level of service expected by the customers is met over the planning horizon.

There is a large body of literature concerning the decision making methods (DMMs) used in water resources planning, but it is necessary that the selection and utilisation of such methods in practice (i.e., for regulatory submissions) are investigated and understood.

\section{Materials and methods}

Water companies' DMMs used for 2014 WRMP submissions and industry guidance documents regarding requirements for 2019 submissions are briefly reviewed in this section. Each company is required to project their water supply position for at least 25 years planning horizon. Baseline supply forecasts include estimation of deployable output, outage, potential transfers, and the operational use or loss of water. Any supply related investment can affect future changes to deployable output (DO) (Figure 1). The deployable output is defined as the output of commissioned sources for a designed drought, which is constrained by hydrological yield, licenses, transfers, treatment and water quality [2].

Historical or stochastic rainfall time series and potential evaporation (PET) time series are used as an input for rainfall-runoff and groundwater models to generate flow sequences for water resources modelling [4]. The stochastically generated rainfall time series "enables assessment and decisionmaking based on metrics of probability and consequence" [5]. The water resources simulation models (e.g., Aquator [6], MISER [7, 8]) with assumed control curves, flows and demand for each system are used to estimate the current deployable output for an assumed level of service.

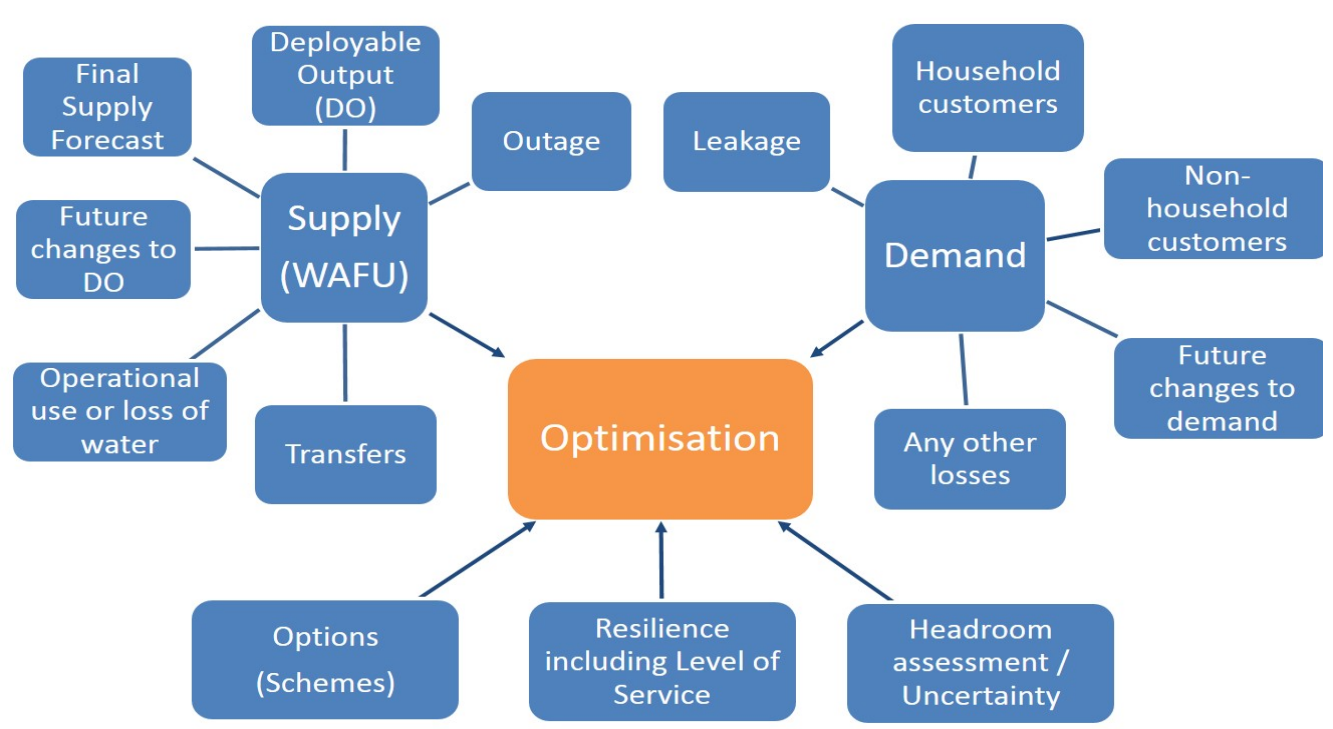

Figure 1: Building blocks of supply demand modelling 
Water companies need to develop demand forecasts that include household and non-household demand, leakage, and water taken unbilled. The household demand is forecasted using the microcomponent models (estimating usage separately for water consuming appliances) [7-9] and nonhousehold demand by employing econometric modelling [9]. The leakage estimation is included on the demand side of the supply demand balance, and current and proposed level of leakage are compared with the Sustainable Economic Level of Leakage (SELL) [4, 7-10].

During the 2014 WRMP process, most of the companies decided to use headroom, defined as the margin between supply and demand [11], to account for risk to their supply-demand positions. Companies tend to use the Monte Carlo simulation to deliver their target headroom time series [7, 8]. Unfortunately, the headroom approach "does not provide information about the likelihood of observable events of interest to water users (i.e., water shortages of different degrees of severity) occurring" [11].

For 2014 WRMP submissions, most water companies used the Economics of Balancing Supply Demand (EBSD) approach as a DMM - in order to evaluate the optimal investment programme under a range of planning scenarios [4, 6, 8-10]. For 2019 WRMP, each company is obliged to undertake a problem characterisation process, in order to assess the complexity of their supply-demand position. Based on problem characterisation outputs (scores), companies should then employ the most appropriate DMM for their plans. Guidance documents specify three potential WRMP approaches: conventional, resilience-tested, and fully risk-based - one of these should be selected by a given company based on the company's problem characterisation and risk composition assessment $[12,13]$.

The proposed risk based methods (RBM) for 2019 WRMP eliminate the need for a target headroom approach. These methods also allow companies to connect particular investment programmes with the relevant level of service [12], "including nonstationary probabilistic climate information and representing multiple sources of uncertainty simultaneously" [14]. It is not clear at the moment how many companies will manage to employ one of the risk based methods for their 2019 WRMP submissions. Guidance documents also suggest that the companies with significant water deficits should proceed from an EBSD approach to more complex approaches including system simulation based planning methods and extended EBSD methods for their 2019 submissions, subject to data availability [13].

A further change at 2019 WRMP is that companies are expected not to use their SELL forecast as a simple input to their investment models. The regulator required that "SELL is fully integrated with WRMP. It should be an output from the WRMP economic analysis and not simply an input to the process" [15]. For 2024 WRMP, it is anticipated that a whole new approach will be required where the assessment of leakage is concerned [15].

There are currently only five draft WRMP 2019 submissions available for review. This paper reviews draft WRMPs 2019 from the following companies: Bristol Water, Severn Trent Water, Southern Water, Thames Water and United Utilities.

\section{Results and discussion}

\subsection{Bristol Water}

The case study of Bristol Water's DMMs used for 2014 WRMP and 2019 WRMP submissions are presented and compared in this section[7, 8]. Bristol Water is a water-only company located in South West England. It serves an area of approximately 2,400 square kilometres, with 1.19 million people in Bristol and surrounding areas. The company, after consultation with its customers, proposes the level of service specified in Table 1 [7]. 
Table 1: Level of Service (2019) proposed by Bristol Water, Southern Water and Thames Water

\begin{tabular}{|c|c|c|c|}
\hline Drought Action & Bristol Water & $\begin{array}{l}\text { Southern Water } \\
\text { years on average }\end{array}$ & Thames Water \\
\hline Advertising to influence water use & & 1 in 5 & 1 in 5 \\
\hline Temporary use ban (TUBs) & 1 in 15 & 1 in 10 & 1 in 10 \\
\hline Drought Order - Non-essential use ban & 1 in 33 & 1 in 20 & 1 in 20 \\
\hline $\begin{array}{l}\text { Emergency Drought Order - Partial } \\
\text { supply or rota-cuts }\end{array}$ & 1 in 100 & $\begin{array}{l}1 \text { in } 500 \text { (only in } \\
\text { civil emergencies) }\end{array}$ & 1 in 125 \\
\hline
\end{tabular}

Bristol Water has taken a similar approach for both their 2014 and 2019 submissions. The company models their supply and demand over 25 years, based on annual data. The deployable output is estimated using MISER [7, 8] and Excel based Mass Balance water resource models (which has been updated for 2019 submission).

Compared with 2014's forecast, the demand forecast for 2019's submission was reduced. In 2014, Bristol Water assumed that an extra $20 \mathrm{Ml} / \mathrm{d}$ would be required for a potential new power station which ultimately proved not to be the case. The company's supply forecast has been reviewed since 2014's submission, and it is estimated that Bristol Water has greater Water Available for Use (WAFU) than it believed it had in 2014. Therefore, Bristol Water's supply-demand position for next 25 years is far better than it previously thought. Owing to the relatively minor potential deficit, Bristol Water decided to reduce their number of feasible options for the 2019 submission [7].

Bristol Water used the Monte Carlo simulation to deliver its headroom uncertainty. The company recognised the following components of uncertainty, affecting their supply-demand balance - on the supply side: gradual pollution, accuracy of supply-side data, and impact of climate change on deployable output; and on the demand side: accuracy of demand data (meter accuracy), demand forecast variation (economic and population growth), impact of climate change on demand, and uncertainty over demand management options. The company models headroom levels separately, with and without a climate change component [7].

In 2014 the company used the WiLCO optimisation model, employing a genetic algorithm [8]. For 2019 submission Bristol Water used the EBSD model based on a multiobjective genetic algorithm. As the deficit anticipated in 2014 seemed to be far more significant, Bristol Water had to consider a greater number of scenarios including the scenario of the construction of a new Cheddar reservoir.

In 2019 WRMP Bristol Water considered 5 scenarios, testing their model against water licences restrictions, household demand increase, potential new non-household demand, the impact of climate change on water resources yield and potential $15 \%$ leakage reduction [7].

Considering the uncertainty in household demand forecast, a 5\% increase in PCC in comparison to the current forecast is assumed. The long-term supply-demand balance can be achieved by leakage reduction, water export reduction, and implementation of drought management options. A 20Ml/d demand increase is assumed to consider the uncertainty in the non-household demand forecast. The long-term supply-demand balance can be achieved by the same project as listed above, with the upgrade of one of the treatment works and customer efficiency projects will be required in addition.

The decision making tools used by Bristol Water and other water companies for their draft WRMP 2019 submissions, are presented in the Table 2. 
Table 2: Decision making tools for WRMP 2019

\begin{tabular}{|c|c|c|c|c|}
\hline & Bristol Water & Severn Trent & Southern Water & Thames Water \\
\hline $\begin{array}{c}\text { Supply } \\
\text { Forecasting }\end{array}$ & $\begin{array}{l}\text { MISER,Mass } \\
\text { Balance Model }\end{array}$ & Aquator & Aquator & $\begin{array}{c}\text { WARMS2,IRAS } \\
\text { model }\end{array}$ \\
\hline $\begin{array}{l}\text { Demand } \\
\text { Forecasting }\end{array}$ & $\begin{array}{l}\text { Micro-component } \\
\text { analysis and linear } \\
\text { regression models }\end{array}$ & $\begin{array}{l}\text { Micro-component } \\
\text { analysis }\end{array}$ & $\begin{array}{c}\text { Micro-component } \\
\text { analysis and } \\
\text { linear regression } \\
\text { models }\end{array}$ & $\begin{array}{l}\text { Multiple linear } \\
\text { regression model, } \\
\text { regression trend } \\
\text { model }\end{array}$ \\
\hline Uncertainty & $\begin{array}{c}\text { Target Headroom } \\
\text { Approach }\end{array}$ & $\begin{array}{l}\text { Target Headroom } \\
\text { Approach }\end{array}$ & $\begin{array}{c}\text { Target } \\
\text { Headroom, } \\
\text { Scenario } \\
\text { Generator Model }\end{array}$ & $\begin{array}{c}\text { Target Headroom, } \\
\text { Monte Carlo } \\
\text { Simulation }\end{array}$ \\
\hline $\begin{array}{l}\text { Investment } \\
\text { program } \\
\text { selection }\end{array}$ & $\begin{array}{l}\text { Multiobjective } \\
\text { EBSD model }\end{array}$ & $\begin{array}{l}\text { WISDM and } \\
\text { DMU }\end{array}$ & $\begin{array}{l}\text { Least cost model, } \\
\text { real options } \\
\text { modelling }\end{array}$ & $\begin{array}{c}\text { EBSD, EBSD+, } \\
\text { IRAS-MCS, } \\
\text { Modelling to } \\
\text { Create } \\
\text { Alternatives, } \\
\text { Multi Criteria } \\
\text { Search } \\
\end{array}$ \\
\hline
\end{tabular}

\subsection{Severn Trent Water [16]}

Severn Trent Water has 15 water resources zones, and recognises potential water abstraction reduction required by way of the Water Framework Directive as the main challenge affecting their future deployable output.

The company employs water resources software - Aquator - for their Deployable Output estimation, and climate change impact modelling, as shown in Table 2. For climate change purposes they use Latin Hypercube Sampling, to sub-sample 100 projections from 10,000 temperature and precipitation change projections.

The company employs micro-component analysis for forecasting household water consumption. Severn Trent uses the target headroom approach to assess uncertainty for modelling purposes. They consider the following source uncertainties to affect them on the supply side: groundwater sources at risk of gradual pollution, accuracy of supply side data, and uncertainty of the impact of climate change. Uncertainties on the demand side of the water balance are accuracy of sub-component demand, demand forecast variation, and uncertainty of the impact of climate change.

The company considers water trading in their WRMP, and offers five trading options to Anglian Water for inclusion in their cost benefit appraisal. However, Anglian's WRMP only includes one water transfer option. Severn Trent also proposes to reduce a water transfer to one of the neighbouring companies, Yorkshire Water.

The company employs the same model for water resources and water infrastructure planning - the Water Infrastructure and Supply / Demand investment model (WISDM) - which allows them to "test the very long term, holistic investment decisions needed to both maintain the performance of water distribution network and improve the balance between future supply and demand". They state that their investment optimisation approach follows "elements of the "intermediate" and "advanced" UKWIR / EA Economics of Balancing Supply and Demand (EBSD) approach". The WISDM model provides least cost solutions and these solutions are used in Monte Carlo analysis to determine a Level 
of Service for the solutions they propose. If estimated Levels of Service do not match, then the headroom used in WISDM is adjusted and WISDM needs to be re-run.

Using their modelling suite, they propose three feasible supply demand investment programmes with "very similar overall programme costs, but using different options". The water import option from a neighbouring company - United Utilities - is not considered in their preferred plan, but that will be reviewed for their final WRMP submission.

For their 2019 WRMP, the company has added Decision Making Upgrade (DMU) enhancement to their WISDM investment model in order to test the sensitivity of their investment plan to planning assumptions. They performed "6,000 DMU supply/demand investment optimisations, covering 60 different possible future scenarios".

\subsection{Southern Water [17]}

Southern Water submitted a draft WRMP with a 50 year planning period, but the strategies they propose only focus on the next 10-15 years. The company's area of supply is divided into 14 water resource zones, whereas their water resource planning was carried out for three areas of supply: Eastern, Central and Western. Southern Water operate in a water-stressed area, as defined by the Environment Agency. The company identified potential abstraction licence reduction to be the greatest challenge affecting their available water resources. The potential scale of the reduction in question will become clear in 2023. The company identified opportunities for collaboration with neighbouring water companies, by way of water transfer and sharing of resources. The company assessed two planning scenarios: dry year annual average (DYAA), and dry year critical period (DYCP), as required by Environmental Agency. The company uses Catchmod hydrogical models and then Aquator water resources model for the DO assessments [17], as shown in Table 2. They proposed Level of Service targets presented in the Table 1.

Southern Water uses micro-component analysis to forecast their household demand. The company recognises population growth and changes in household composition as key drivers for increased demand.

The company uses a target headroom approach to assess uncertainty. They use an "integrated risk model" to provide target headroom estimates, by including demand and supply uncertainty; and demand and supply variability. They propose alternative methods to access uncertainty, by employing a "Scenario Generator Model" that "quantifies risk by simulating a range of possible outcomes, the probabilities of their occurrence and generating a range of supply-demand profiles that occur at different drought scenarios".

For their demand forecast, the company examines uncertainties in: population growth, customer behaviour, and climate change; and for supply forecast uncertainties in climate change, bulk imports and sustainability reductions.

For investment strategy decision-making, they first run a 'least cost' model without any constraints. The output of this run is then tested by modifying assumptions about the availability of options, or including potential delays to the delivery of options. These alternative scenarios are considered through the real options method [17], which allows company to understand the impact of such assumptions on the proposed strategy. Real option modelling allows the company to replace the traditional target headroom approach, in order to assess risk and uncertainty.

\subsection{Thames Water [18]}

Thames Water, the biggest water company operating in England, provides water to around 10 million household customers and 215,000 businesses. They divide their operational area into six water resource zones (WRZs). Thames' WRMP covers an 80 year planning horizon. Thames Water Level of Service for their customers is presented in the Table 1. 
The company assumes that non-household water demand is correlated with wider economic trends. They use a regression trend model - with number of employees, population numbers and tariff rates as the explanatory variables.

For their draft WRMP19, they developed a multiple linear regression (MLR) model to forecast household consumption up to the year 2100. Their MLR uses the following explanatory variables:

- Number of adults

- Number of children

- South Asian Ethnic Group flagged property type flag

- Non-IBP flagged property type flag

- Rateable value (RV), defined as valuation of a property based on its size, location and other factors

Thames Water uses their Water Resources Management System Model (WARMS2) to calculate their DO. Rainfall and PET data are used in a Catchmod-based rainfall/runoff model, to generate multiple 100 year time series of River Thames and River Severn flows. The River Thames flows are used as an input to the Integrated River Aquifer System (IRAS) model [18]. The IRAS model provides a mass-balance analysis, and has been chosen by the company because it is much faster than the WARMS2 model.

Thames Water uses a target headroom approach to handle the uncertainty in supply demand planning. They use a Monte Carlo simulation to provide their headroom assessment.

The company performs a problem characterisation assessment, in order to determine the complexity of the supply demand problem in all of their WRZs. For zones with low complexity they use EBSD modelling to provide the optimal investment programme; for zones with more challenging supply demand positions they use EBSD + and Interactive River-Aquifer Simulation (IRAS-MCS) models.

The models are coupled to optimisers which use Modelling to Generate Alternatives or Multi Criteria Search (MCS) to find a range of potential solutions. In the next step these solutions are evaluated by experts. The company states that IRAS-MCS will be completed for their final WRMP.

\subsection{United Utilities [19]}

United Utilities provides water supplies to a population of 7.1 million people; and to around 200,000 non-household customers in the North West of England. Their plan covers a 25 year planning horizon. United Utilities assume Level of Service presented in the Table 1.

The company state that "it is unacceptable to plan for rota cuts or standpipes even during extreme drought conditions". United Utilities' problem characterisation assessment showed the moderate complexity of the supply demand problem - hence more sophisticated decision making tools than EBSD should be considered.one

The company uses micro-component analysis for its household consumption forecast, as shown in Table 2. For non-household consumption modelling they use econometric models with the following explanatory variables: total output in the non-service sector (output growth), and full-time equivalent employment in the service sector (employment growth).

For their high complexity zones the company used the Aquator software to assess DO, whereas for low complexity zones the output from source yield assessment was satisfactory for DO estimation. They also use the Aquator model for climate change impact assessment. United Utilities use a Strategic Resource Zone emulator, utilising the Pywr modelling platform [19]- for rapid DO assessment, when capturing the full complexity of their supply system is not required. For their outage assessment, they use Monte Carlo simulation; for their uncertainty assessment, a target headroom assessment.

United Utilities use the EBSD model as a decision support tool for selecting an optimal investment programme. They elect to use one of the extended decision support methods: a combination of 
Scenario Simulation and Robust Decision Making; and they employ both Aquator and Pywr software for this purpose.

\section{Conclusions}

The majority of water companies prepare their WRMPs following the same methodology forecasting supply, demand, and target headroom. For 2019 submissions, as a result of the addition of the problem characterisation requirement, companies need to review their baseline supply demand position and then choose the most appropriate DMMs. In the case study presented, Bristol Water prepared their WRMP19 based on a similar methodology to that employed for their WRMP14 submission and chose similar DMMs. The outcome of their problem characterisation exercise suggests that more sophisticated DMMs are not required by Bristol Water - hence continued use of the target headroom approach. It is, however, anticipated that this approach would be replaced with a simulation method for the company's 2024 WRMP submission.

Companies with more challenging supply-demand positions (i.e. Southern Water and Thames Water) prepared their draft WRMPs using more sophisticated methods. Every company analysed here decided to represent their uncertainty by way of a target headroom approach; but Thames Water also decided to progress to a system simulation approach (MCS).

\section{References}

[1] Ofwat, Consulting on our methodology for the 2019 price review. 2017.

[2] Environment Agency,Natural Resources Wales,Final Water Resources Planning Guideline 2016.

[3] Environment Agency, Ofwat, Defra and the Welsh Government, Water resources planning guideline. The technical methods and instruction 2012.

[4] Southern Water. Water Resources Management Plan 2015-40. 2014.

[5] Turner SWD, Blackwell RJ, Smith MA, Jeffrey PJ. Risk-based water resources planning in England and Wales: challenges in execution and implementation. Urban Water Journal 2016;13(2):182-97.

[6] Severn Trent Water. Final Water Resources Management Plan 2014. 2014.

[7] Bristol Water, Draft Water Resources Management Plan. Bristol Water; 2017.

[8] Bristol Water, Water Resources Management Plan 2014. 2014.

[9] Thames Water, Water Resources Management Plan 2014. 2014.

[10] South West Water, Water Resources Management Plan 2014. 2014.

[11] Hall J, Borgomeo E. Risk-based principles for defining and managing water security. Philosophical Transactions of the Royal Society A: Mathematical, Physical and Engineering Sciences 2013;371(2002).

[12] UKWIR, WRMP 2019 Methods -Decision Making Process: Guidance. 2016.

[13] UKWIR, WRMP 2019 Methods -Decision Making Process: Risk Based Planning. 2016.

[14] Borgomeo E, Hall JW, Fung F, Watts G, Colquhoun K, Lambert C. Risk-based water resources planning: Incorporating probabilistic nonstationary climate uncertainties. Water Resources Research 2014;50(8):6850-73.

[15] Environment Agency, Leakage in WRMPs, June 2017. 2017.

[16] Severn Trent, Draft Water Resources Management Plan 2018.

[17] Southern Water, Water Resource Management Plan 2019: Technical Overview. 2018.

[18] Thames Water. Our water resources management plan 2019. 2018.

[19] United Utilities. Draft Water Resources Management Plan 2019. 2018. 